\title{
QUANTITATIVE ASSESSMENT OF THERMAL FEATURES \\ OF THE SOUTHWEST PORTION OF YELLOWSTONE PARK
}

\author{
William T. Parry \\ David S. Chapman \\ John R. Bowman \\ Richard G. Allis \\ The University of Utah
}

\section{Objectives}

The objectives of this project are to obtain chemical, thermal, and hydrological data for thermal features in the southwest portion of Yellowstone National Park, and to make assessments of the heat, mass, and chemical budgets for the region. With a better understanding of the hydrothermal regime we intend to delineate key thermal features which should be monitored on a periodic basis to detect inadvertent geothermal development impact.

\section{Assessment of Water Chemistry}

Quantitative assessment of the thermal features of the southwest portion of Yellowstone Park requires measurement of the chemical composition of thermal fluids and an estimate of the geological processes leading to the observed compositions. Processes which should be evaluated include equilibration of the fluid with minerals, steam separation, mixing of thermal fluids with cold water, and irreversible mass transfer among minerals and fluid.

Water samples were collected from the following thermal areas: Upper Boundary Creek, Middle Boundary Creek, Lower Boundary Creek, Silver Scarf, Bechler Ford, Mountain Ash, Three Rivers, and Summit Lake. Collection procedures followed the method of Presser and Barnes (1974). The samples have been analyzed using the methods outlined in Brown et al. (1970) and American Public Health Association (1971) and analytical results are shown in Table 1. Quartz saturation temperatures and $\mathrm{Na}-\mathrm{K}-\mathrm{Ca}$ temperatures are also shown in Table 1.

\section{Results}

Silica contents of water samples are shown in Figure 1 with saturation curves for amorphous silica and quartz. All of the waters are supersaturated with quartz and some are near amorphous silica saturation at their measured temperatures. The springs all issue from volcanic rocks rich in glass, but the flow path may have included other lithologies: 


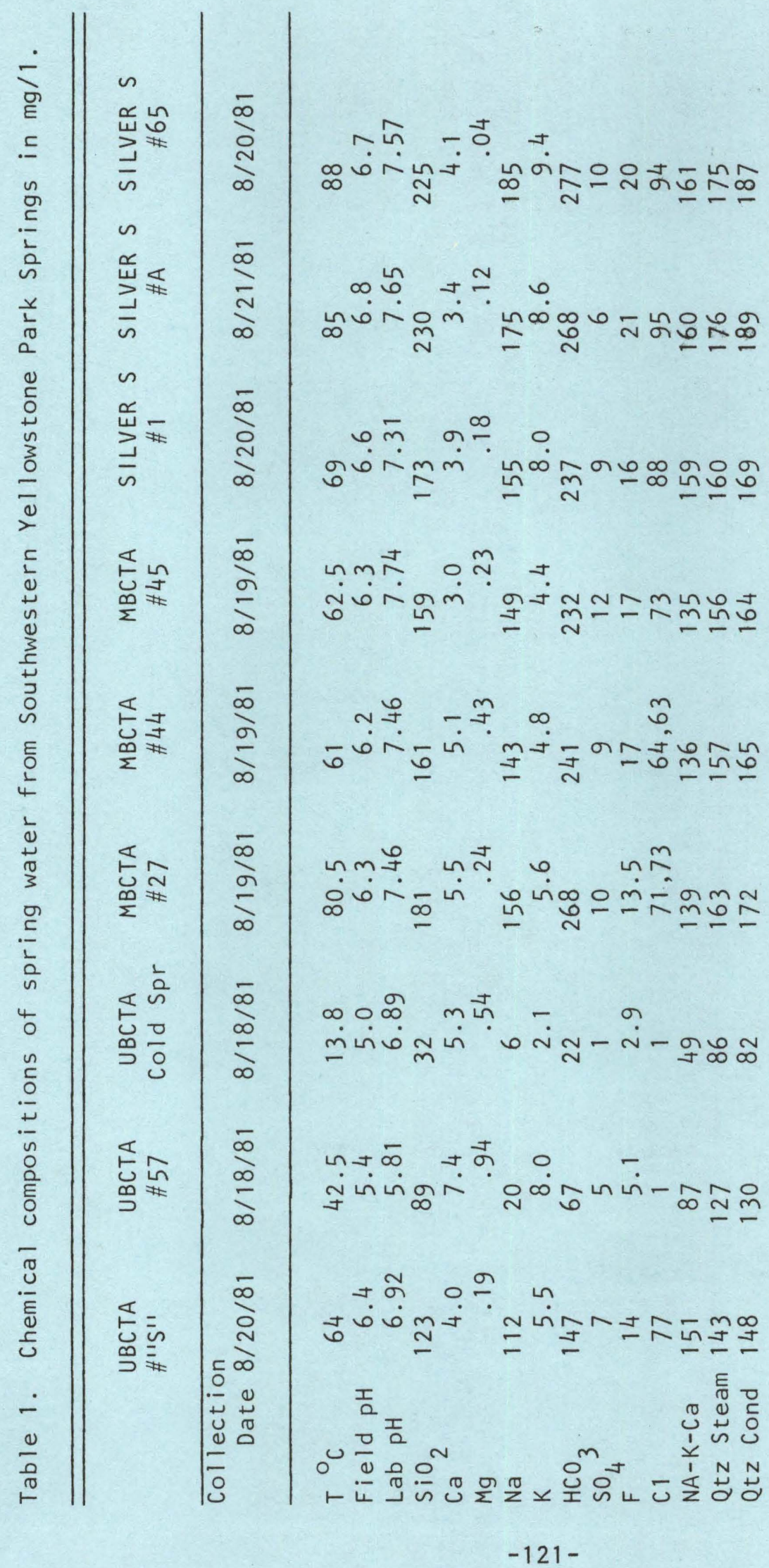




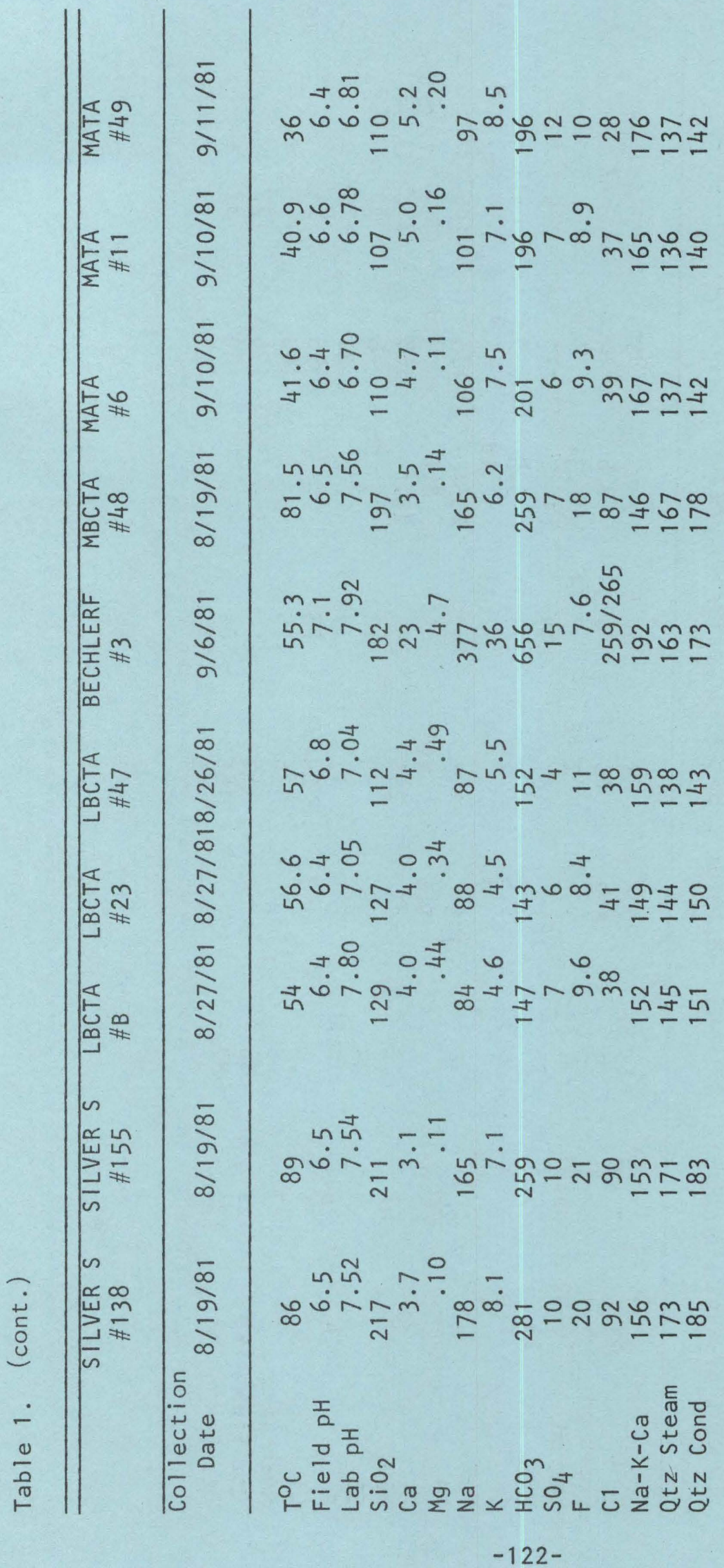




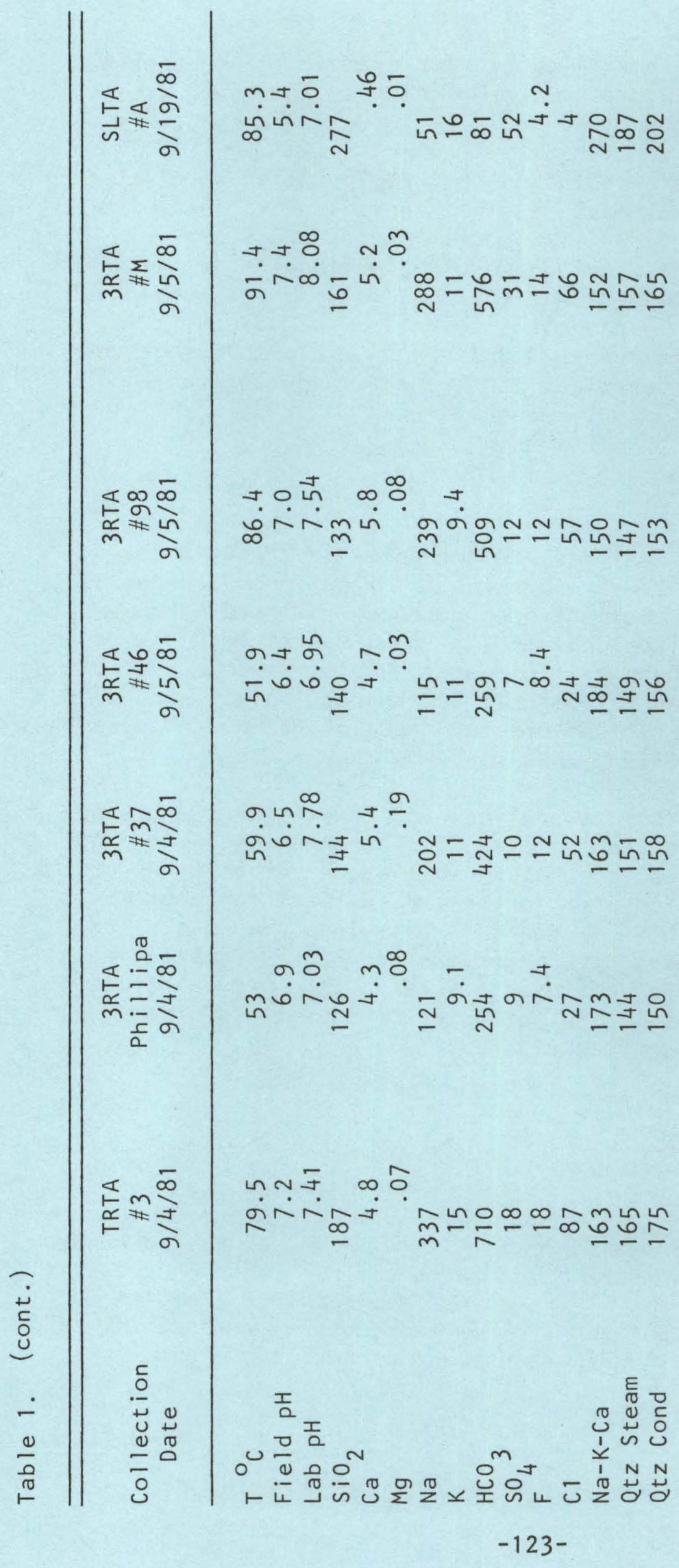


fractures armored with hydrothermal quartz for example. The observed silica in water is a function of the thermal history and minerals to which the water has been exposed.

We have attempted to use the dissolution and precipitation kinetics of Rimstidt and Barnes (1980) to model possible thermal histories which will produce the observed silica. The model results are shown in Figure 1. Models shown do not include more conventional models involving steam separation and mixing of hot and cool solutions which are also possible, or even likely, explanations. We are not able at this stage of the investigation to choose among the possible models or combinations but will use other chemical constituents and isotopes to assist in the choice.

\section{Stable Isotope Analysis}

Hydrogen and oxygen isotope analyses are currently underway on water samples collected in the southwest portion of Yellowstone Park during August and September, 1981. Collection procedures followed methods recommended by Nehring and Truesdell (1977). Analytical methods for oxygen and hydrogen isotope analysis of water samples follow those of Epstein and Mayeda (1953) and Friedman (1953, respectively. Both hydrogen and oxygen isotope compositions are reported in the "delta" notation relative to SMOW (Craig, 1961).

At this time, all hydrogen-isotope analyses and ten of the twenty-one oxygen-isotope analyses have been completed. These analyses are presented in Table 2. Both hydrogen and oxygen isotope compositions of the waters vary significantly from area to area. The total range of $\delta D$ values, -117 to -140 is within the range of $\delta D$ values previously reported for other thermal areas within Yellowstone Park (Truesdell et al., 1977). When all analyses are completed, isotopic and chemical constituents can be compared to assist in interpreting subsurface processes affecting the waters in these thermal areas.

\section{Assessment of Thermal Discharge}

Water discharge and simultaneous temperature and chloride measurements were made at 83 sites in the 8 thermal areas. Temperature measurements were consistent with earlier measurements but flow values varied considerably, indicating annual or seasonal effects that will be important in planning a monitoring program. Thirteen soil temperature profiles yielded a high correlation between shallow temperatures and vegetation type, indicating that aerial photographs can be used to map heat loss in the vapor dominated areas. 
Table 2. $\delta^{18} 0$ and $\delta D$ Values of Southwest Yellowstone Waters.

\begin{tabular}{|c|c|c|c|}
\hline & Sample & $\delta^{18} 0$ & $\delta D$ \\
\hline \multirow[t]{5}{*}{$3 R T A^{a}$} & $\# 3$ & -17.8 & -133 \\
\hline & $\# 37$ & -16.5 & -130 \\
\hline & $\# 46$ & -17.0 & -129 \\
\hline & Ferris Fork \#M & -17.3 & -130 \\
\hline & Phillips Fork & -16.5 & -128 \\
\hline \multirow[t]{3}{*}{ MATA } & $\# 6$ & & -120 \\
\hline & $\# 11$ & -17.8 & -118 \\
\hline & $\# 49$ & -18.6 & -117 \\
\hline \multirow[t]{3}{*}{ LBCTA } & B & & -139 \\
\hline & 23 & & -133 \\
\hline & 47 & & -140 \\
\hline \multirow[t]{3}{*}{ MBCTA } & 27 & -16.8 & -130 \\
\hline & 45 & & -125 \\
\hline & 48 & -15.9 & -128 \\
\hline \multirow[t]{3}{*}{ UBCTA } & Cold Spring & & -139 \\
\hline & Swimming Hole & & -136 \\
\hline & \#57 (North Annex) & -15.6 & -129 \\
\hline SLTA & A & & -133 \\
\hline \multirow[t]{2}{*}{ Silver Scarf } & $\# 65$ & & -122 \\
\hline & $\# 138$ & & -123 \\
\hline Bechler Ford & $\# 3$ & & -124 \\
\hline
\end{tabular}

a Abbreviations are: 3 RTA $=$ Three Rivers Thermal Area; MATA = Mountain Ash Thermal Area; LBCTA $=$ Lower Boundary Creek Thermal Area; MBCTA = Middle Boundary Creek Thermal Area; UBCTA = Upper Boundary Creek Thermal Area; SLTA = Summit Lake Thermal Area. 
Figure 1. Dissolved silica and temperatures of southwest Yellowstone spring waters with hypothetical reaction paths. Open circles - Upper Boundary Creek, filled circles - Three Rivers, triangles - Mountain Ash, open stars - Lower Boundary Creek, filled stars - Middle Boundary Creek, open squares - Silver Scarf, square/star - Summit Lake, circle/star - Bechler Ford. 


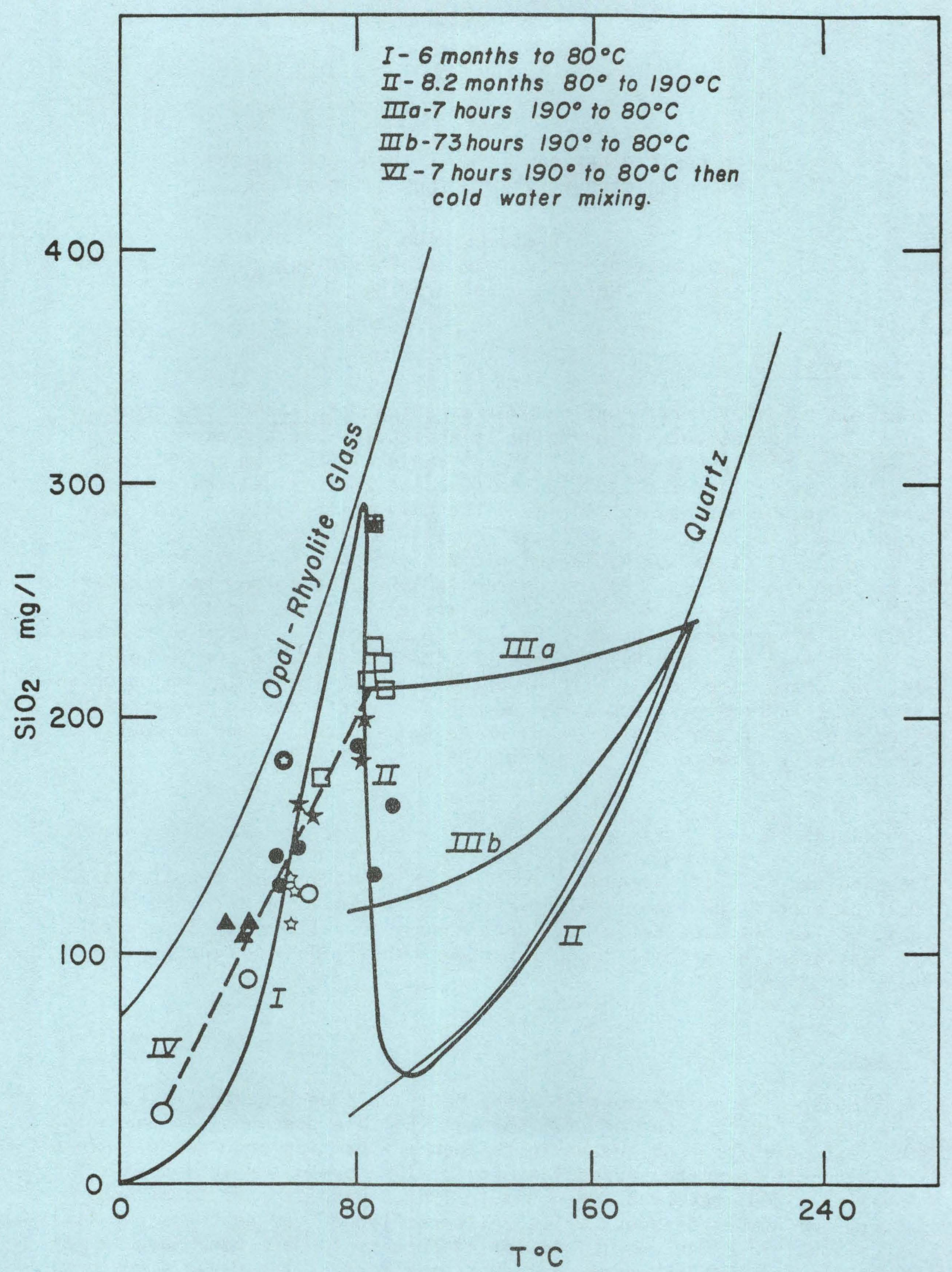

